\title{
Effect of maternal dietary exclusion on breast fed infants with eczema: two controlled studies
}

\author{
A J CANT, J A BAILES, R A MARSDEN, D HEWITT
}

\begin{abstract}
Thirty seven breast fed infants with eczema were studied to see whether changes in their mothers' diets affected their skin condition. Nineteen mothers and babies took part in a double blind crossover trial of exclusion of egg and cows' milk, and 18 took part in open exclusion of 11 foods followed by double blind challenge to those mothers whose infants seemed to respond. Babies were examined at the beginning and end of each dietary period, and the extent and severity of the rash were given a numerical score. The eczema improved in six infants when their mothers avoided egg and cows' milk and worsened again when these were reintroduced. Two infants suffered gastrointestinal reactions after maternal ingestion of egg and cows' milk, one developing colitis.
\end{abstract}

Maternal dietary exclusion seems to benefit some breast fed babies with eczema.

\section{Introduction}

It is ancient wisdom that breast fed infants may react to foods in their mothers' diets. Over 60 years ago Talbot described a breast fed baby whose eczema was provoked by maternal ingestion of chocolate $^{1}$ and O'Keefe reported on several infants with eczema whose rashes were said to improve when their mothers avoided foods such as cows' milk, egg, fish, and oats. ${ }^{2}$ With the recent

Department of Child Health, St George's Hospital Medical School, London SW17 ORE

A J CANT, MD, MRCP, Agriculture and Food Research Council/Medical Research Council training fellow in clinical nutrition

Department of Dermatology, St George's Hospital, London SW17 ORE J A BAILES, BSC, SRD, dietitian

R A MARSDEN, MB, MRCP, consultant dermatologist

Department of Food Quality and Human Nutrition, Institute of Food Research, Reading Laboratory, Shinfield, Reading, Berkshire RG2 9AT

D HEWITT, PHD, principal scientific officer

Correspondence to: Dr A J Cant, Royal Alexandra Hospital for Sick Children, Brighton, Sussex BN1 3JN. resurgence of breast feeding further reports have been published. In 1979 Gerrard described 18 breast fed infants with various symptoms related to foods eaten by their mothers, of whom six presented with eczema. ${ }^{3}$ Cows' milk, egg, oranges, and chocolate were usually cited as being responsible, though double blind challenges were not performed. Only the relation between infantile colic and maternal ingestion of cows' milk has been the subject of controlled studies, two of the three studies being performed double blind. ${ }^{46}$ Two studies found a positive association, and it was concluded that one third of breast fed babies with colic improved if their mothers excluded cows' milk from their diet.

We previously described a series of 49 infants with eczema who were solely breast fed, 23 of whom yielded positive results to skin prick tests with egg or cows' milk.' Furthermore, egg and cows' milk proteins were found in the milk of most mothers two to four hours after an oral challenge with these foods. ${ }^{8}$ We therefore carried out a controlled study of the effect of egg and cows' milk in the maternal diet on breast fed infants with eczema.

\section{Patients and methods}

We studied 37 breast fed infants aged 6 weeks to 6 months, who were referred by doctors, by health visitors, or through voluntary organisations such as the National Childbirth Trust and the National Eczema Society. As it is sometimes difficult to differentiate atopic eczema from other forms of eczema in early infancy we used criteria similar to those of Yates et al. ${ }^{9}$ All the infants had an eczematous rash on the face and extensor surfaces but relative sparing of the napkin area; all were scratching or had a first degree relative with allergic disease, or both. Infants with seborrhoeic dermatitis were excluded. All infants were skin prick tested against egg, cows' milk, chocolate, cod, mixed nuts, and wheat using Bencard extracts.

\section{FIRST TRIAL}

The first trial lasted for 12 weeks and was divided into three periods of four weeks. Throughout the first two periods the mothers excluded all cows' milk, egg, chocolate, wheat, nuts, fish, beef, chicken, citrus fruits, colourings, and preservatives from their diets. During the first period they were allocated to take one of two milk substitutes using a table of random numbers; during the second period they took the other substitute. The substitutes were provided in powdered form for reconstitution with water: one was a soya preparation and the other contained cows' milk and egg powder. The mothers were asked to reconstitute the powder so that they 
received the equivalent of one pint of milk a day and, during one period, one egg a day. Mothers were asked to use the milk as they would normally, and most took it with cereal or porridge. The substitutes were given double blind, and although no flavourings were added fewer than half of the mothers correctly distinguished them. During the third period the mothers were asked to return to a normal diet. The diets were supervised by a dietitian (JAB), the mothers keeping a diary of all they ate. Any mother who lapsed more than four times in one period or who took less than an average of half a pint of milk substitute a day was excluded from the study.

At the beginning and end of each dietary period the babies were examined; their body surfaces were divided into 20 areas, and each area was recorded as affected or unaffected, giving an area score of up to 20. Each area was then given an activity score as follows: $0=$ unaffected, $1=$ minimal change, $2=$ widespread erythema or excoriation or vesiculation, and $3=$ exudation and crusting; thus the maximum activity score was 60 . If topical steroid ointments were used the tubes of ointment were weighed at the beginning and end of each dietary period and the weight of ointment applied recorded.

\section{SECOND TRIAL}

Because of concern that maternal ingestion of soya might have provoked symptoms in the first trial we designed a second. This was in two phases, the first of which lasted six weeks. In the first phase the mothers were asked to ensure that they took a normal diet, containing at least a pint of milk a day and three eggs a week, for two weeks. They then followed the exclusion diet (as in the first trial) for two weeks and finally returned to the diet containing cows' milk and egg for two weeks. Their diet and their infants' rashes were assessed as in the first trial. Babies whose activity scores decreased by more than $20 \%$ when their mothers took the exclusion diet and increased by more than $20 \%$ when their mothers returned to the normal diet were deemed to have responded to the open trial, and their mothers were invited to take part in the second phase.

The second phase lasted for four weeks (two periods of two weeks), and the mothers again took the exclusion diet. During one two week period the mothers took the milk substitute containing cows' milk and egg powder, and during the other they took a similar milk substitute based on potato starch (this was chosen as a placebo as it is not a protein and is extremely unlikely to provoke an allergic response). The milk substitutes were given in a random double blind manner.

\section{STATISTICAL ANALYSIS}

Mean scores before and at the end ( 12 weeks) of the first trial were tested for significant differences by the paired $t$ test. The same test was applied in the second trial to compare the scores recorded after the period on the normal diet and after the period on the exclusion diet and those recorded after the exclusion diet and the second period on the normal diet.

The activity and area scores from the first trial for the period when milk substitutes were given were subjected to standard analysis of variance for a crossover trial. ${ }^{10} \mathrm{We}$ had intended that one group of infants should receive the soya substitute first and that a second group, equal in size to the first, should be given the substitute containing egg and cows' milk first. When the trial was terminated the groups comprised nine and eight subjects, respectively, and the analysis was completed using the missing value technique. Each difference between treatment means was tested for significance using the standard error of difference based on the residual error mean square (with 15 degrees of freedom) from the analysis of variance.

\section{Results}

\section{FIRST TRIAL}

Nineteen mothers entered the first trial and 17 completed it. Twelve infants were solely breast fed, and the remaining five were given at least five breast feeds a day but received small amounts of rice, root vegetables, and non-citrus fruit as well. None were given cows' milk or egg, and no new solids were introduced during the trial. There were eight male and nine female infants. Eight reacted positively to skin prick tests: seven to egg, six to cows' milk, three to chocolate, and one to wheat. One mother vomited after taking the soya milk and so withdrew. Another mother withdrew because her baby developed eczema and bloody diarrhoea within 24 hours of her taking the milk substitute containing cows' milk and egg and eczema alone two days after she took the soya milk substitute. Both reactions were repeated on subsequent challenges, and this case has been described elsewhere. ${ }^{11}$ Two mothers were taking a diet free of cows' milk when first seen, and one would not take cows' milk during the final period of normal diet. Exclusion of these three women did not significantly affect the results.
Individual babies varied greatly in their response to changes in their $\underline{\sigma}$ mother's diet. The activity scores of four babies decreased by more than $20 \%$ when their mothers took the soya milk substitute and increased by at least $20 \%$ when they took the substitute containing cows' milk and egg and when they returned to a normal diet. One of these infants developed watery stools with mucus when his mother took the substitute containing cows' milk and egg. One baby's score deteriorated by $20 \%$ when her mother took soya milk $\overline{\bar{J}}$ substitute and improved by over $20 \%$ when she took the substitute containing cows' milk and egg, only to relapse again when her mother took a normal diet. The skin condition remained unchanged throughout the trial in four infants, deteriorated steadily in one, and improved steadily in seven. The figure shows the changes in activity scores when the mothers took the two milk substitutes.

\section{Substitute containing cows'milk and egg powder Soya substitute}

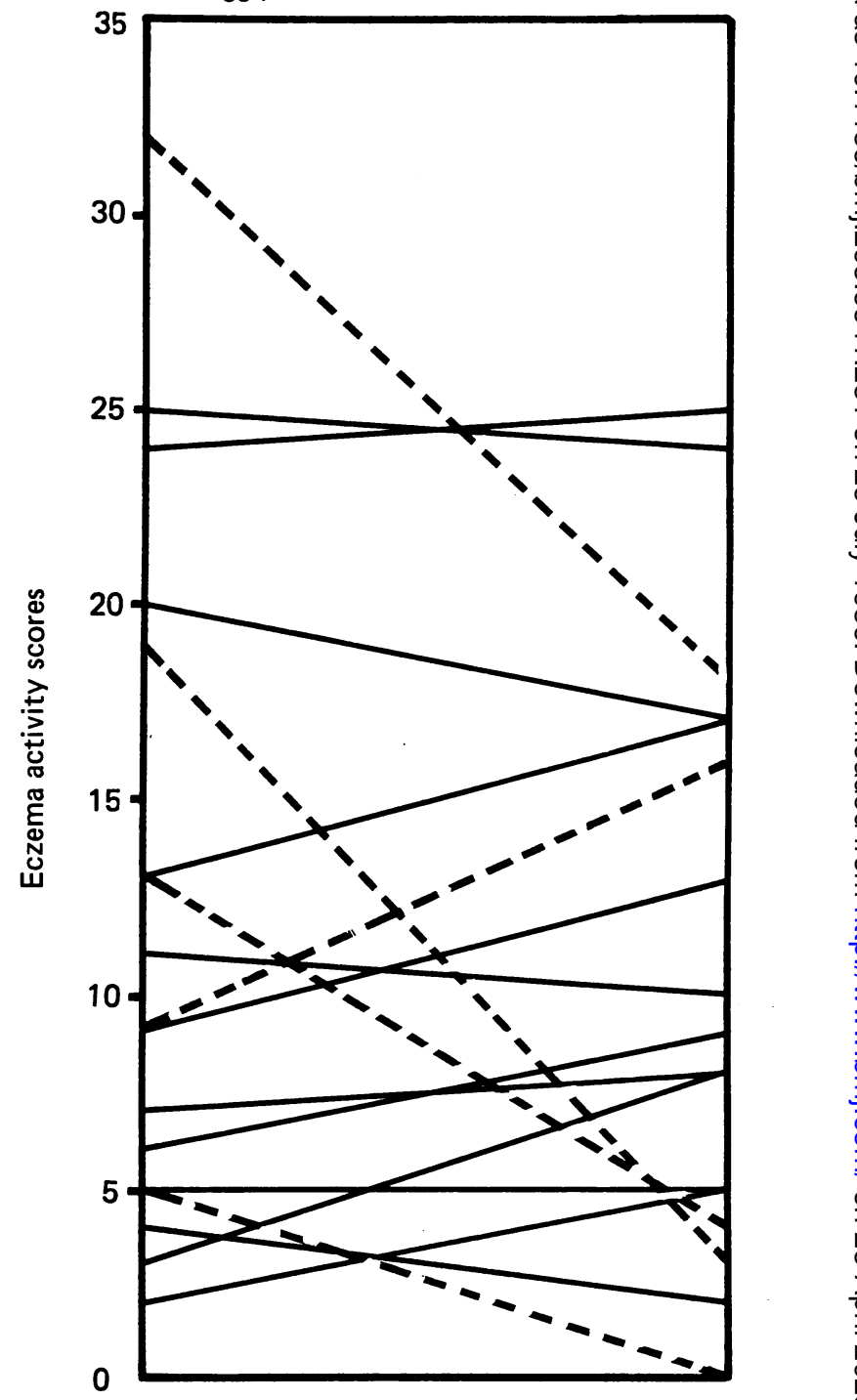

Comparison of individual eczema activity scores after mothers had taken each milk substitute for four weeks; half the mothers took the substitute containing cows' milk and egg first, and half took the soya substitute first. Broken lines indicate infants who seemed to respond to these changes in maternal diets.

In terms of mean values diet had little effect (table I). Mean scores decreased during the trial, and at the end of the study, after the mothers had $\mathbb{D}$ returned to a normal diet for four weeks, the scores were significantly lower than they had been at the beginning, when the mothers were taking the same diet $(\mathrm{p}<0.01)$. This decrease occurred during the first experimental period regardless of which milk substitute was being taken. There was no difference $\delta$ between overall mean scores after the first and second four week periods on the exclusion diet, and although they were lower with the soya milk substitute than with the substitute containing cows' milk and egg, the differences were small relative to the standard errors. The weight of steroid cream applied in each period was not significantly different. 
TABLE I-Effect of maternal diet on infants' eczema: first trial. (Values are means or means $(S D)$ )

\begin{tabular}{|c|c|c|c|c|c|c|}
\hline Diet & $\begin{array}{c}\text { Before } \\
\text { trial } \\
(n=17)\end{array}$ & $\begin{array}{l}\text { At } 4 \\
\text { weeks } \\
(n=9)\end{array}$ & $\begin{array}{l}\text { At } 8 \\
\text { weeks } \\
(n=9)\end{array}$ & $\begin{array}{c}\text { At } 12 \\
\text { weeks } \\
(n=17)\end{array}$ & $\begin{array}{l}\text { Mean } \\
\text { at end of } \\
\text { exclusion } \\
\text { diet }\end{array}$ & $\begin{array}{l}\text { SE of difference } \\
\text { between } \\
\text { exclusion diet } \\
\text { means }(\mathrm{df}=15)\end{array}$ \\
\hline \multicolumn{7}{|c|}{ Activity score } \\
\hline $\begin{array}{l}\text { Exclusion + soya } \\
\text { substitute }\end{array}$ & (19) & $10 \cdot 4$ & $11 \cdot 2 \dagger$ & & $10 \cdot 8$ & \multirow[b]{2}{*}{1.62} \\
\hline $\begin{array}{l}\text { Exclusion + sub- } \\
\text { stitute containing } \\
\text { egg and cows' milk }\end{array}$ & & $12 \cdot 6 t$ & $11 \cdot 8$ & & $12 \cdot 2$ & \\
\hline Mean at end of period & & $11 \cdot 5$ & $11 \cdot 5$ & & & \\
\hline \multicolumn{7}{|c|}{ Area score } \\
\hline $\begin{array}{l}\text { Exclusion + soya } \\
\text { substitute } \\
\text { Exclusion + sub- } \\
\text { stitute containing } \\
\text { egg and cows' milk }\end{array}$ & & $9 \cdot 0$ & $8 \cdot 3 t$ & & $8 \cdot 6$ & 0.98 \\
\hline Mean at end of period & & $9 \cdot 0$ & $9 \cdot 1$ & & & \\
\hline
\end{tabular}

^Difference between means at ends of two periods on normal diet were significant $(p<0.01)$. Differences between exclusion diets and between periods were not significant. tOne missing value.

\section{SECOND TRIAL}

Eighteen mothers entered this trial, and all completed the first phase. All the babies were exclusively breast fed throughout. There were 12 male and six female infants, and nine reacted positively to skin prick tests: seven to egg, six to cows' milk, and two to chocolate. In two children the activity score decreased by more than $20 \%$ when their mothers took the exclusion diet and then increased by more than $20 \%$ when their mothers returned to a normal diet. In two infants the activity scores remained unchanged when their mothers took the exclusion diet but then deteriorated when the mothers took a normal diet. Four infants' rashes did not change, and 10 improved steadily through all periods (table II). Table II shows the average

TABLE II-Second trial: mean (SD) eczema scores after mothers had taken normal and exclusion diets $(n=18)$

\begin{tabular}{lccc}
\hline & $\begin{array}{c}\text { At 2 weeks } \\
\text { (after normal diet) }\end{array}$ & $\begin{array}{c}\text { At 4 weeks } \\
\text { (after exclusion diet) }\end{array}$ & $\begin{array}{c}\text { At 6 weeks } \\
\text { (after normal diet) }\end{array}$ \\
\hline Activity score & $17 \cdot 2(7 \cdot 7)$ & $13 \cdot 2(8 \cdot 6)$ & $14 \cdot 1(6 \cdot 7)$ \\
Area score & $13 \cdot 2(4 \cdot 8)$ & $10 \cdot 7(5 \cdot 9)$ & $10 \cdot 7(6 \cdot 7)$ \\
\hline
\end{tabular}

activity and area scores after each period and table III the changes between periods and their significance. After two weeks of the exclusion diet average scores were considerably reduced (activity $\mathrm{p}<0.001$, area $\mathrm{p}<0.01$ ). After a further two weeks when the mothers took the normal diet, however, average values were virtually unchanged.

Only one of the two mothers whose babies' skin seemed to be considerably improved by the exclusion diet agreed to take part in the double blind phase; this baby's activity score increased by more than $20 \%$ when the mother took the substitute containing milk and egg and then decreased by more than $20 \%$ during the placebo period, confirming that maternal ingestion of egg and cows' milk provoked his eczema. In both trials positive reactions to skin prick tests with egg and cows' milk were equally common among responders and non-responders.

\section{Discussion}

There are many reports of breast fed babies whose allergic signs and symptoms were said to be related to their mother's diet..$^{1-312} 13$ The two trials described here, however, suggest that most breast fed babies with eczema do not respond to maternal dietary manipulation. This is despite the finding that 17 of the 37 infants showed cutaneous hypersensitivity to either or both of egg and cows' milk (foods not apparently ingested directly) and that egg and cows' milk proteins are detected in most mothers' milk. ${ }^{8}$ Nearly half $(46 \%)$ of
TABLE III-Second trial: mean (SE) changes in eczema scores with change in maternal $\operatorname{diet}(n=18)$

\begin{tabular}{lcc}
\hline & $\begin{array}{c}\text { Change from normal to } \\
\text { exclusion diet }\end{array}$ & $\begin{array}{c}\text { Change from exclusion to } \\
\text { normal diet }\end{array}$ \\
\hline Activity score & $-4 \cdot 1(0 \cdot 98)^{\star \star}$ & $0 \cdot 9(1 \cdot 40)$ \\
Area score & $-2 \cdot 4(0.83)^{\star}$ & $0 \cdot 0(0 \cdot 89)$ \\
\hline
\end{tabular}

Significance of change: ${ }^{\star} p<0.01,{ }^{\star \star} p<0.001$.

the babies showed an improvement in their eczema during the exclusion periods, so that if the mothers had not returned to a normal diet we would have thought that dietary exclusion was beneficial, when in fact the improvement was probably spontaneous. This effect would have been greater still if we had included babies with seborrhoeic dermatitis, as this condition almost invariably remits spontaneously. ${ }^{9}$ It is also conceivable, though unlikely, that maternal dietary exclusion improved the babies' eczema but that rechallenge did not then provoke the condition. This could be ruled out only by comparing the study infants with a matched group of infants whose mothers remained on a normal diet throughout.

In six of the 37 babies who entered the trials, however, the eczema did seem to respond by both improving when the mothers avoided egg and cows' milk and relapsing when these foods were reintroduced. Two of the infants suffered gastrointestinal reactions, and in one this was too severe for his mother to continue in the trial. No specific factors predicted which babies would respond to maternal dietary exclusion, and in particular skin prick tests with egg and cows' milk were unhelpful. Interestingly, the two babies who suffered gastrointestinal reactions both gave negative reactions to skin prick tests with foods. It might be argued that the overall negative result of the first trial was due to the use of soya milk as the placebo, as this can provoke allergic reactions ${ }^{14}$ and did so in one of our cases. ${ }^{11}$ Nevertheless, the results were no different from those of the second trial, when no placebo was given in the first phase and potato starch was given in the second.

Eczema in breast fed infants has a high rate of spontaneous improvement, which is often wrongly attributed to maternal dietary exclusion; nevertheless, a subgroup of such babies do seem to be genuinely affected by foods in their mothers' diets, especially egg and cows' milk. It is probably sensible for mothers who are breast feeding babies with eczema or gastrointestinal symptoms to avoid egg and cows' milk completely for a trial period of two weeks and then return to a normal diet. Only if this produces a considerable improvement and then deterioration in their child's condition should they return to an exclusion diet, and then it should be with dietetic help to ensure nutritional adequacy.

JAB was supported by a South West Thames Regional Health Authority research grant. Wyeth Laboratories kindly supplied the milk substitutes.

\section{References}

1 Talbot FB. Eczema in childhood. Med Clin North Am 1918;1:985-96.

2 O'Keefe ES. The relation of food to infantile eczema. Boston Medical and Surgical foumal 1920;183:569-73.

3 Gerrard JW. Allergy in breast fed babies to ingredients of breast milk. Ann Allergy 1979;42:69-72.

4 Jakobsson I, Lindberg T. Cows' milk as a cause of infantile colic in breast fed infants. Lancet 1978;ii:437-9.

5 Evans RW, Fergusson DM, Allardyce RA, Taylor B. Maternal diet and infantile colic in breast fed infants. Lancet $1981 ;$ i: 1340-2.

6 Jakobsson I, Lindberg T. Cows' milk proteins cause infantile colic in breast fed infants: a double blind cross-over trial. Pediatrics 1983;71:268-71.

7 Cant AJ, Marsden RA, Kilshaw PJ. Egg and cows' milk hypersensit ivity in exclusively breast fed infants with eczema, and the detection of egg protein in breast milk. Br Med $\mathcal{F}$ 1985;291:932-5.

8 Kilshaw PJ, Cant AJ. The passage of maternal dietary proteins into human breast milk. In $\boldsymbol{t}$ Arch Allergy Appl Immunol 1984;75:8-15.

9 Yates VM, Kerr REI, Mackie RM. Early diagnosis of infantile seborrhoeic dermatitis and atopic eczema-clinical features. Br f Dermatol 1983;108:633-8.

10 Cochran WG, Cox GM. Experimental designs. 2nd ed. New York: John Wiley and Sons, 1957:127.

11 Cant AJ. Bailes JA, Marsden RA. Cows' milk, soya milk and goats' milk in a mother's diet causing eczema and diarrhoea in her breast fed infant. Acta Paediatr Scand 1985;74:467-8.

12 Lake AM, Whitington PF, Hamilton SR. Dietary protein induced colitis in breast fed infants. J Pediatr 1982;101:906-10.

J Pediatr 1982;101:906-10.
13 Warner JD. Food allergy in fully breast fed infants. Clin Allergy 1980;10:133-6.

14 Visakorpi JK. Milk and soybean protein allergy. Fournal of Paediatric Gastroenterology and Nutrition 1983;2 (suppl 1):S293-7.

(Accepted 25 May 1986) 